University of Nebraska - Lincoln

DigitalCommons@University of Nebraska - Lincoln

Faculty Publications from the Harold W. Manter Laboratory of Parasitology

2-1996

\title{
Burhinotaenia colombiana n. sp. (Cestoda, Cyclophyllidea) from the Double-Striped Stone Curlew Burhinus bistriatus (Aves, Charadriiformes) in Colombia
}

\author{
Boyko B. Georgiev \\ Bulgarian Academy of Sciences \\ Éva Murai \\ Hungarian Natural History Museum \\ Robert L. Rausch \\ University of Washington, rausch@uw.edu
}

Follow this and additional works at: https://digitalcommons.unl.edu/parasitologyfacpubs

Part of the Parasitology Commons

\begin{abstract}
Georgiev, Boyko B.; Murai, Éva; and Rausch, Robert L., "Burhinotaenia colombiana n. sp. (Cestoda, Cyclophyllidea) from the Double-Striped Stone Curlew Burhinus bistriatus (Aves, Charadriiformes) in Colombia" (1996). Faculty Publications from the Harold W. Manter Laboratory of Parasitology. 389. https://digitalcommons.unl.edu/parasitologyfacpubs/389
\end{abstract}

This Article is brought to you for free and open access by the Parasitology, Harold W. Manter Laboratory of at DigitalCommons@University of Nebraska - Lincoln. It has been accepted for inclusion in Faculty Publications from the Harold W. Manter Laboratory of Parasitology by an authorized administrator of DigitalCommons@University of Nebraska - Lincoln. 


\title{
BURHINOTAENIA COLOMBIANA N. SP. (CESTODA, CYCLOPHYLLIDEA) FROM THE DOUBLE-STRIPED STONE CURLEW BURHINUS BISTRIATUS (AVES, CHARADRIIFORMES) IN COLOMBIA
}

\author{
Boyko B. Georgiev, Éva Murai, and Robert L. Rausch† \\ Institute of Ecology, Bulgarian Academy of Sciences, 2 Gagarin Street, 1113 Sofia, Bulgaria
}

\begin{abstract}
Burhinotaenia colombiana $\mathrm{n}$. sp. (Dilepididae) is described from the small intestine of the double-striped stone curlew Burhinus bistriatus (Burhinidae) captured at Carimagua, Colombia. The new species is distinguished from the most similar Burhinotaenia delachauxi (Baer, 1925), a parasite of the Old World Burhinus spp., by the longer cirrus-sac (375-590, avg. 514 $\mu \mathrm{m}$ vs. $322-393$, avg. $354 \mu \mathrm{m})$ and longer rostellar hooks $(412-451$, avg. $440 \mu \mathrm{m}$ vs. 358-367, avg. $364 \mu \mathrm{m})$. The validity of the genus Burhinotaenia Spasskii and Spasskaya, 1965 and its generic diagnosis as proposed by Bona (1994) are confirmed. This is the first record of a species of Burhinotaenia in the New World.
\end{abstract}

The double-striped stone curlew Burhinus bistriatus (Wagler) occurs in Central America and northern South America, from southern Mexico to northern Colombia and northern Brazil (Howard and Moore, 1980). The only record of cestodes from this host was reported by Beddard (1913) who described the dilepidid tapeworm Eugonodaeum oedicnemi Beddard, 1913 from a bird at the London Zoo.

Three cestode species were found as parasites of $B$. bistriatus in Colombia. The present paper describes 1 of them, which was found to represent a new species of the genus Burhinotaenia Spasskii and Spasskaya, 1965. The systematic position of the other 2 species is a subject of another study that will be published separately.

\section{MATERIAL AND METHODS}

The present description is based on 8 entire specimens, 1 separate scolex, and a few fragments collected by R. L. and V. R. Rausch on 6 April 1977 from the small intestine of 1 female $B$. bistriatus (collection no. 42,671) captured at Carimagua, Colombia. They were fixed in hot $10 \%$ formalin, stored in $70 \%$ ethanol, stained in iron acetocarmine, dehydrated, cleared in eugenol, and mounted in Canada balsam. Two scoleces were mounted in Berlese's fluid in order to provide detailed observations of rostellar hooks. Mature, pregravid, and gravid proglottides of 1 specimen were sectioned transversely by hand with a razor blade to facilitate study of some anatomical details.

Metric and meristic characteristics are given as the range, the mean $\pm 1 \mathrm{SD}$ in parentheses, and the number of measurements or counts taken (n). The dimensions are in micrometers except where otherwise stated.

The type specimens were deposited in the U.S. National Parasite Collection, Beltsville (USNPC), the Parasitological Collection of the Department of Zoology, Hungarian Natural History Museum, Budapest (HNHM), and the collection of the senior author (BBG).

The type specimens of Burhinotaenia delachauxi (Baer, 1925) from the collection of the Natural History Museum, Geneva, nos. 6/24-25 (2 slides) and a specimen of Burhinotaenia coronata from Burhinus oedicnemus (Linnaeus), the Great Hungarian Plain, from the Parasitological Collection of the Hungarian Natural History Museum, Budapest, no. 10907 (published as B. delachauxi by Murai et al. [1988]), were used as comparative material.

Received 12 September 1994; revised 21 August 1995; accepted 21 August 1995.

* Department of Zoology, Hungarian Natural History Museum, Baross utca 13, H-1088 Budapest, Hungary.

$\dagger$ Department of Comparative Medicine SB-42, University of Washington, Seattle, Washington 98195.

\section{DESCRIPTION}

Burhinotaenia colombiana n. sp.

(Figs. 1-15)

Strobila bandlike, when gravid 66-94 $\mathrm{mm}(77 \pm 9 \mathrm{~mm}, \mathrm{n}=7)$ long, consisting of 296-356 (314 $\pm 21, \mathrm{n}=7)$ proglottides, 8-38 $(23 \pm 9, \mathrm{n}$ $=7)$ of them gravid; maximum width $1,488-2,012(1,706 \pm 180, \mathrm{n}=$ 7) at gravid proglottides, rarely at pregravid proglottides. Scolex (Figs. $1,2)$ distinct from neck, rounded laterally, with maximum width 986$1,135(1,042 \pm 56, n=7)$ at level of suckers; apical part forms cuplike cavity bearing crown of rostellar hooks; walls of cavity protrusible. Suckers prominent, oval, highly muscularized, with diameter 310-390 $(340 \pm 20, n=28)$. Rostellum heartlike, wider near anterior end, gradually tapering posteriorly; in posterior direction reaching end of scolex and passing slightly into neck; 734-849 (794 $\pm 43, \mathrm{n}=7)$ long and 493-505 (502 $\pm 6, n=7)$ wide. Lacking saclike rostellar sheath, only strongly developed muscular bundles surround rostellum. Rostellar hooks 24-28 $(26 \pm 1, n=9)$ in number, directed anteriorly and arranged in single crown; each hook consists of chitinoid part (with long and slightly curved blade, short handle, and bifid guard), and amorphous case comprising handle and guard of chitinoid part (Figs. 3-7), which takes stain; hook measurements: general length (a) 412-451 (440 $\pm 11, \mathrm{n}=20)$, length of chitinoid part (b) 336-371 (362 $\pm 8, n=20)$, length of blade (c) 246-264 (254 $\pm 4, n=20)$, length of base of chitinoid part (d) 107$125(118 \pm 5, \mathrm{n}=19)$, length of hook base (e) 170-208 (193 $\pm 12, \mathrm{n}$ = 20); vary in narrower limits in 1 scolex, e.g., (a) 439-451, (b) 356371 , (c) 249-259, (d) 114-123, (e) 192-208 ( $=14)$. Neck 402-585 $(478 \pm 70, n=7)$ wide in narrowest part. Segmentation begins at about $1,444-1,772(1,590 \pm 118, \mathrm{n}=7)$ from posterior margin of suckers. Proglottides (Figs. 8-11) craspedote, wider than long; mature proglottides with length/width ratio $1 / 4.1-1 / 2.8(1 / 3.3 \pm 0.4, \mathrm{n}=10)$; gravid proglottides with length/width ratio $1 / 2.7-1 / 2.2(1 / 2.5 \pm 0.2, \mathrm{n}=10)$. Genital pores irregularly alternating, mainly in short series, e.g., . . 2, $1,2,1,1,2,4,4,1,1,1,1,1,2,1,3,5,2,1,1,10,2,1,1,1,3,1,5$, $1,1,1,2,1,4,4,3,1,3$; opened in middle of lateral proglottis margin on tall, slightly expressed genital papilla. Genital atria (Fig. 12) infundibular, with well expressed circular musculature of tubular base; $38-$ $48(43 \pm 4, n=10)$ deep, with diameter of tubular part 13-20 (16 \pm $2, \mathrm{n}=10)$. Ventral osmoregulatory canals $23-59(38 \pm 14, \mathrm{n}=10)$ wide; with transverse anastomosis along posterior margin of every proglottis. Dorsal osmoregulatory canals 7-13 $(9 \pm 2, \mathrm{n}=10)$ wide. Genital ducts between osmoregulatory canals.

Testes 17-32 $(24 \pm 3, n=38$, taken from 7 strobila $)$ in number; their number varies in narrower limits in 1 strobila, e.g., 17-22 $(n=6), 19-$ $25(n=6), 22-25(n=6), 22-27(n=6), 24-32(n=6)$; major part of testes (Figs. 8, 9) situated in mature proglottides in 2 groups laterally to vitellarium and laterally and posteriorly to ovary wings; single testes occasionally disposed posteriorly and dorsally to vitellarium; testes do not extend laterally beyond longitudinal osmoregulatory canals; vestigial testes might be present along posterior margin of pregravid and gravid proglottides. External vas deferens coiled both ventrally and dorsally to cirrus-sac, covered with single layer of large, intensely stained cells (Fig. 12); its diameter 11-28 $(18 \pm 6, \mathrm{n}=15)$. Cirrus-sac (Fig. 12) thick- 

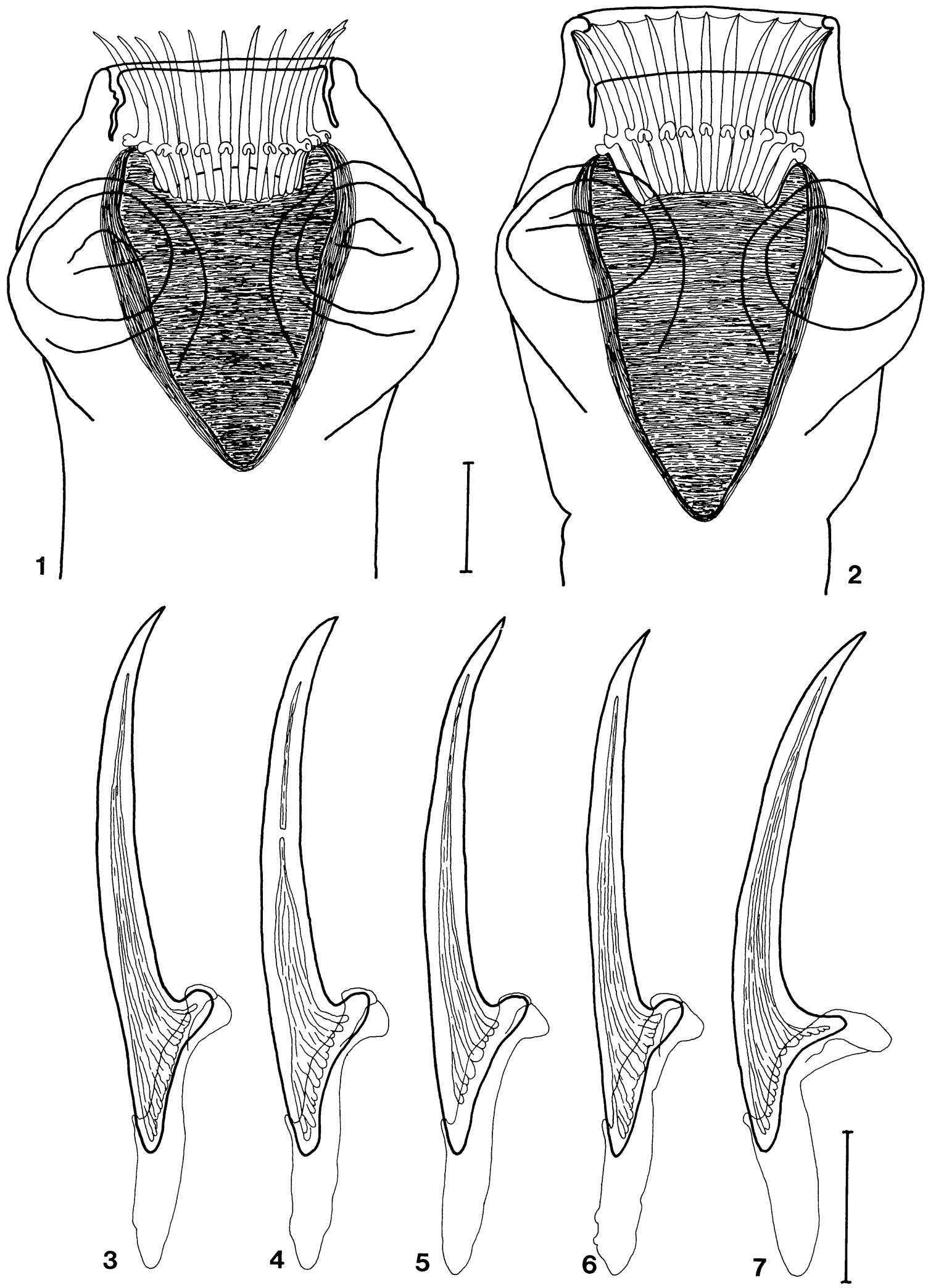

Figures 1-7. Burhinotaenia colombiana n. sp. 1, 2. Scoleces, scale bar $250 \mu \mathrm{m}$. 3-7. Rostellar hooks, scale bar $=100 \mu \mathrm{m}$. 
142 THE JOURNAL OF PARASITOLOGY, VOL. 82, NO. 1, FEBRUARY 1996
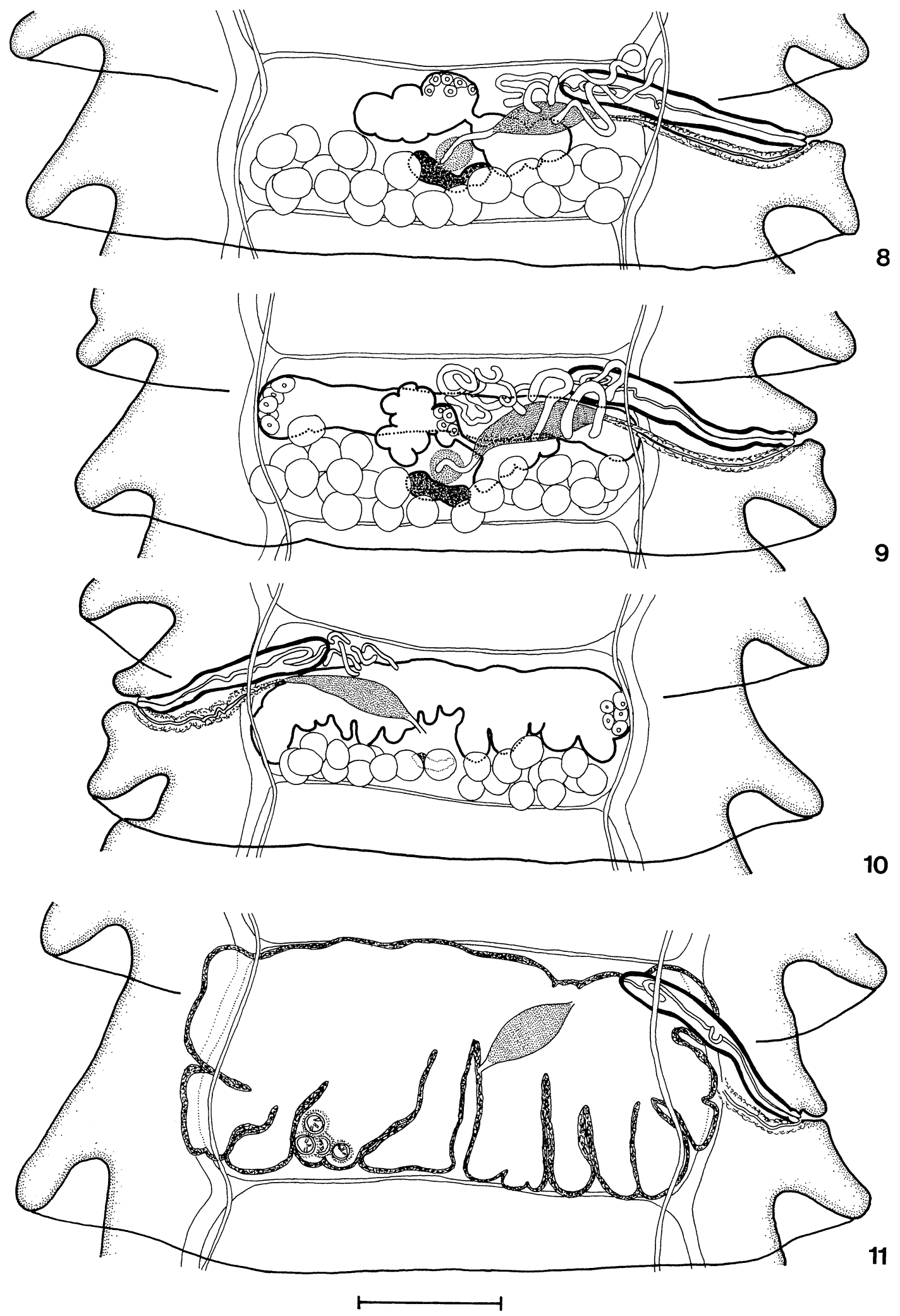

Figures 8-11. Burhinotaenia colombian n. sp. 8, 9. Mature proglottides. 10. Postmature proglottis. 11. Gravid proglottis. All views dorsal. Scale bar $=250 \mu \mathrm{m}$. 

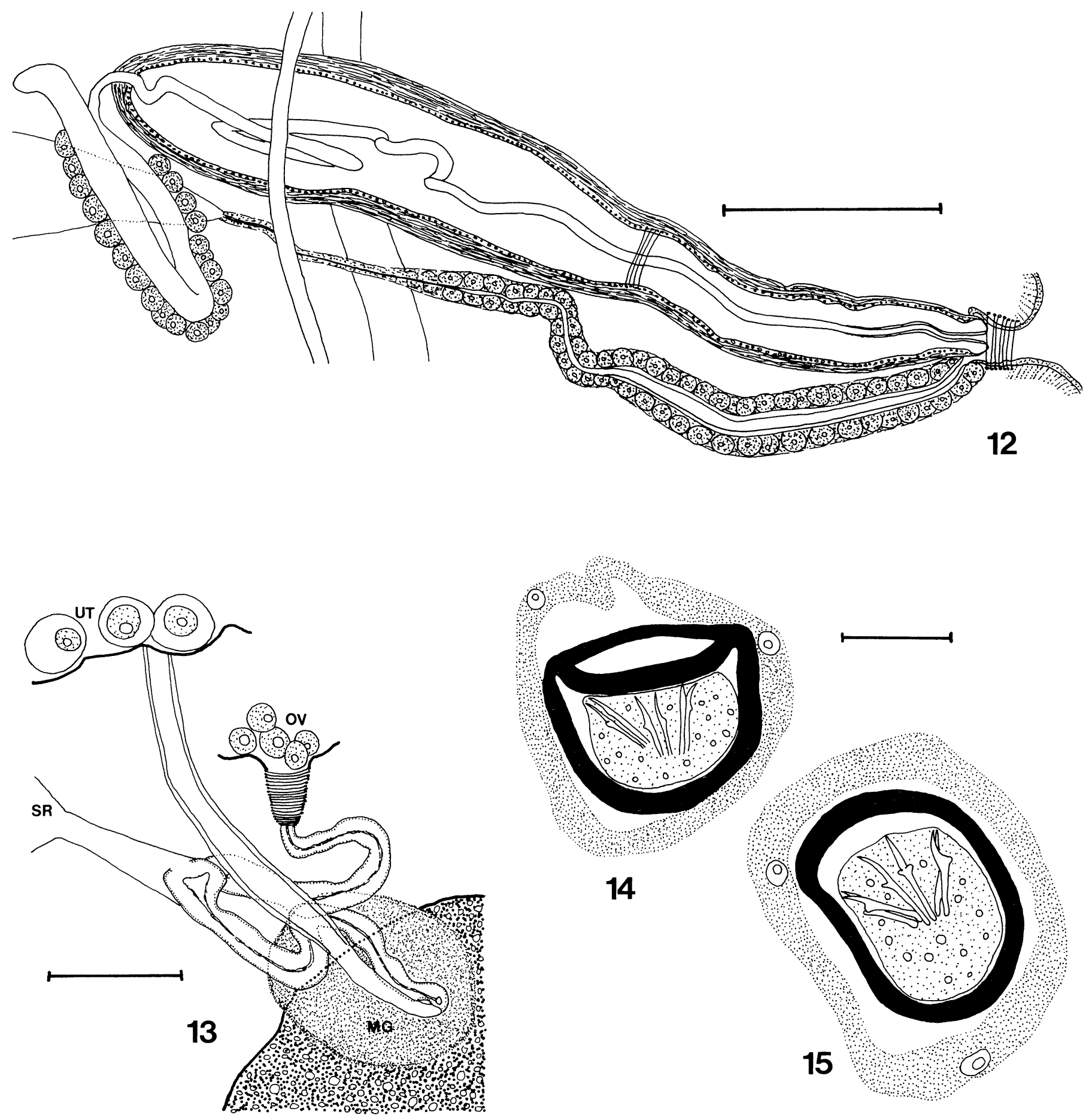

FIGURES 12-15. Burhinotaenia colombiana n. sp. 12. Terminal genital ducts, dorsal view, scale bar $=100 \mu \mathrm{m}$. 13. Detail of female genital ducts, ventral view, scale bar $50=\mu \mathrm{m}$; abbreviations: $M G$, Mehlis' gland; $O V$, ovary; $S R$, seminal receptacle; $U T$, uterus. 14, 15. Eggs, scale bar $=20 \mu \mathrm{m}$.

walled, highly elongate, claviform (with wider aporal end), often sigmoid; its measurements 375-590 × 54-85 (514 $\pm 44 \times 66 \pm 7, \mathrm{n}=$ 49), vary in narrower limits in 1 strobila, e.g., $375-491 \times 54-67(\mathrm{n}=$ 6), 456-532 × 63-72 (n=9), 483-554 × 67-81 (n=8), 528-590 $\times$ 58-67 ( $=8)$; situated obliquely, cross poral longitudinal osmoregulatory canals and about a third or a quarter of it lies in median field. Internal vas deferens forming 1 or a few coils in aporal part of cirrussac. Cirrus usually slightly evaginated, then almost conical, 16-25 (19 $\pm 4, \mathrm{n}=10)$ long and $12-17(14 \pm 2, \mathrm{n}=10)$ wide at base; thoroughly evaginated cirrus occurs rarely, cylindrical, $77-107(93, n=3)$ long, with diameter $12-15(13, \mathrm{n}=3)$; armament observed neither on evaginated cirrus nor in ductus cirri.

Vitellarium compact, transversely elongate, usually reniform, situated near middle of posterior proglottis margin. Ovary (Fig. 8) occupies only central third of median field; consists of 2 separate wings connected by narrow isthmus; wings slightly lobed; aporal wing more anterior than 
poral. Mehlis' gland distinct, globular (Fig. 13). Seminal receptacle from fusiform to lemon-shaped, situated in poral half of median field, anterior to poral wing of ovary and posterior to cirrus-sac; $201-254(233 \pm 17$, $\mathrm{n}=10)$ long, 54-81 (66 $\pm 8, \mathrm{n}=10)$ wide. Vaginal orifice (Fig. 12) posterior to male pore; vagina passing posteriorly to cirrus-sac; vaginal lumen with diameter 3-5 $(4.5 \pm 0.7, \mathrm{n}=10)$, with distinct muscular walls surrounded by thick cellular sleeve; diameter of vagina (together with cellular sleeve) $25-32(29 \pm 2, \mathrm{n}=10)$.

Uterus initially appears in mature proglottides (Fig. 9) as transversely elongate sac along anterior proglottis margin, ventral to ovary; its ends do not cross longitudinal osmoregulatory canals. This sac expands gradually in posterior direction and its posterior margin forms numerous sacculations in postmature proglottides (Fig. 10). Gravid uterus (Fig. 11) thick-walled, occupies median field, its ends sometimes overlap longitudinal ventral osmoregulatory canals; small portions of uterus rarely in lateral fields; walls persistent up to end of uterine development. Fully developed eggs (Figs. 14, 15) almost globular or with irregular shape, with granular outer envelop (not clearly seen in whole mounts); diameter 50-63 $(56 \pm 3, n=10)$. Embryophore very thick, highly refractive, oval or goblet-like, with diameter $39-46(44 \pm 2, n=10)$. Oncosphere round to oval or with irregular shape near to oval, thinwalled, with diameter 27-34 $(31 \pm 2, \mathrm{n}=10)$. Embryonic hooks 3 pairs, central pair 18-19 $(18.8 \pm 0.4, \mathrm{n}=8)$ long, lateral pairs $15-16(15.9$ $\pm 0.4, \mathrm{n}=8$ ) long.

\section{Taxonomic summary}

Type host: Double-striped stone curlew, B. bistriatus (Wagler). Type locality: Carimagua, Colombia.

Site: Small intestine.

Specimens: Holotype USNPC 85055 (1 slide). Paratypes USNPC 85056-85057 ( 2 specimens, 12 slides); HNHM 67008/1-3 (3 specimens, 3 slides); BBG 1995.6.6.1-4 (2 entire specimens, 1 scolex, and 2 fragments; 4 slides).

Etymology: The specific name, colombiana, refers to the country where the specimens were collected.

\section{Remarks}

The genus Burhinotaenia Spasskii and Spasskaya, 1965 was erected for 2 species described from birds of the family Burhinidae (Charadriiformes): B. delachauxi (Baer, 1925) (type species) and Burhinotaenia megistacantha (Fuhrmann, 1909). They were separated from the genus Paricterotaenia Fuhrmann, 1932 on the basis of their enormous rostellar hooks (about 3 times larger than the hooks of the type-species $P$. porosa (Rudolphi, 1810)) and some peculiarities of genital organs, in particular the structure of the gravid uterus considered to form egg capsules (Spasskii and Spasskaya, 1965). According to Spasskaya and Spasskii (1978), the genus Burhinotaenia includes 2 valid species: (1) Burhinotaenia delachauxi (Baer, 1925) Spasskii and Spasskaya, 1965, synonyms Icterotaenia delachauxi Baer, 1925; Choanotaenia delachauxi (Baer) Lopez-Neyra, 1935; Paricterotaenia coronata of Mahon (1954) and Baer (1959); and (2) Burhinotaenia coronata (Creplin, 1829) Spasskaya and Spasskii, 1978, synonyms Taenia coronata Creplin, 1829; Choanotaenia coronata (Creplin) Fuhrmann, 1909; Paricterotaenia coronata (Creplin) Fuhrmann, 1932; Choanotaenia megistacantha Fuhrmann, 1909; Icterotaenia megistacantha (Fuhrm.) Baer, 1925; Paricterotaenia megistacantha (Fuhrm.) Fuhrmann, 1932; Sacciuterina megistacantha (Fuhrm.) Mathevossian, 1963; Burhinotaenia megistacantha (Fuhrm.) Spasskii and Spasskaya, 1965; Choanotaenia delachauxi var. mesacantha Lopez-Neyra, 1935; Choanotaenia magnihamata Burt, 1940.

Fuhrmann and Baer (1943) re-examined the original Creplin's specimens and recognized $P$. delachauxi as a junior synonym of $P$. coronata. This synonymy was followed by Mahon (1954) and Baer (1959). In contrast to the conclusion of Mahon (1954), her precise drawings of rostellar hooks from the types of $P$. coronata and from her specimens from a charadriiform host from Zaire clearly demonstrated 2 different types of hook shape. On the basis of this publication, Spasskaya and Spasskii (1978) considered the shape of rostellar hooks as the main distinguishing character between $B$. delachauxi and $B$. coronata: the former is characterized with ratio length of blade : length of base about 1.5:1; the latter has rostellar hooks with almost equal lengths of blade and base. Considering this differentiating feature, the conclusion is that the specimen of Burhinotaenia from Burhinus oedicnemus from Hun- gary determined as $B$. delachauxi and possessing rostellar hooks with length of the blade 115-160 and length of the handle 120-150 (Murai et al., 1988) belongs to $B$. coronata.

Dr. F. V. Bona (pers. comm.) examined the rostellar hooks of the type of $B$. coronata from the Collection of the Natural History Museum, Geneva (no. 28/42) and confirmed that they correspond to the drawing of Mahon (1954) for the same material; he found that the ratio length of blade: length of base of these hooks is $0.85-1.1: 1$.

Because the synonymy proposed by Spasskaya and Spasskii (1978) is based on a study of the literature, it can be accepted only conditionally and needs further confirmation grounded on a reexamination of the relevant specimens. Moreover, the data on the strobilar anatomy of most of the nominal taxa considered as synonyms of $B$. coronata or $B$. delachauxi are scarce, and only the morphology of rostellar hooks can be used for reliable comparisons. The synonymy of Spasskaya and Spasskii (1978), however, reflects the presence of 2 types of rostellar hook shape in the known nominal species of Burhinotaenia, and this character is the main one applied further in the differential comparison of the new species.

The shape of the rostellar hooks of $B$. colombiana $\mathbf{n}$. sp. is close to those of $B$. delachauxi. The hitherto reported lengths of the hooks of this species are 370 (Baer, 1925), 360-388 (Mahon, 1954), and 366375 (Baer, 1959). The present observations on type specimens of $B$. delachauxi revealed that their hooks are 358-367 $(364, \mathrm{n}=8)$ long; $\mathrm{Dr}$. F. V. Bona (pers. comm.) measured a minimum length of 337 for the rostellar hooks of types of $B$. delachauxi. The new species with rostellar hooks $412-451$ (440) long is clearly distinguished from $B$. delachauxi by this character. A full comparison between the anatomy of proglottides of $B$. colombiana and $B$. delachauxi is difficult due to the rather contracted condition of the types of the latter and the scarce literature data. Nevertheless, a considerable difference in the dimensions of the cirrus sac was established, i.e., 375-590 $\times$ 54-85 $(514 \times 66)$ of $B$. colombiana and 322-393 $\times 40-45(354 \times 42, n=6)$ of the types of $B$. delachauxi. In addition, the only scolex from the types of $B$. delachauxi available for measuring has metric characters under the range of dimensions of the new species, i.e., diameter of scolex 975 , diameter of suckers 250 $268(258, n=4)$, rostellum 562 long and 459 wide.

\section{DISCUSSION}

After the separation of Burhinotaenia from Paricterotaenia by Spasskii and Spasskaya (1965), its validity was supported only in a subsequent publication of the same authors (Spasskaya and Spasskii, 1978). Schmidt (1986) recognized B. delachauxi and $B$. coronata as members of the genera Polycercus Villot, 1883 (syn. Paricterotaenia) and Choanotaenia Railliet, 1896, respectively, i.e., he regarded Burhinotaenia as a synonym of Polycercus although the generic name was not included in the list of synonyms. Recently, Bona (1994) validated Burhinotaenia and amended its generic diagnosis.

The present study confirms the peculiar structure of the rostellar apparatus of Burhinotaenia spp., characterized by the absence of a saclike rostellar sheath. It is completely different from the rostella of the majority of dilepidid genera, including these of Paricterotaenia, Choanotaenia and Polycercus. According to Bona (1994), this type of rostellar apparatus, termed as onderstepoortioid, occurs only in the genera Burhinotaenia, Onderstepoortia Ortlepp, 1938, and Spreotaenia Spasskii, 1969. However, Burhinotaenia differs obviously from the latter 2 genera by its strobilar morphology. Therefore, the present study on the new species and its comparison with the types of the type species of Burhinotaenia confirm the opinion of Bona (1994) about the validity of this genus and do not support the generic allocations of its species as proposed by Schmidt (1986).

The present results are also in agreement with the generic diagnosis of Burhinotaenia proposed by Bona (1994). However, there is an exception with respect to the structure of the gravid 
uterus. According to the key of Bona (1994), the uterine walls of Burhinotaenia are not persistent and the eggs are loose in parenchyma in the final stage of uterine development. In well stained specimens of the new species, the uterine walls are seen up to the end of the development of the organ.

The peculiar scolex structure of Burhinotaenia and the other 2 genera with an onderstepoortioid rostellar apparatus makes questionable their position within the family Dilepididae because most of the genera (including the type genus Dilepis Weinland, 1858) possess rostella with saccular sheaths. The characteristics that the absence of a saccular rostellar sheath, in combination with the saclike uterus without a paruterine organ and the avian host, resemble cestodes of the family Metadilepididae. The metadilepidids are a small family (8 genera) of avian parasites morphologically similar to both Dilepididae and Paruterinidae; they can be distinguished from the former by the absence of a saccular rostellar sheath and the position of the developing uterus dorsal to the ovary, and from the latter by the absence of a paruterine organ (Kornyushin and Georgiev, 1994). In spite of the similarity of Burhinotaenia with the metadilepidids, it cannot be placed among them because of the ventral position of its uterus to the female glands. It seems that none of the cyclophyllidean families erected up to the moment may harbor the genus Burhinotaenia, but the erection of a new family could be well grounded only as a part of a thorough revision of the order. Therefore, Burhinotaenia is tentatively retained in the Dilepididae pending further revisions of the order Cyclophyllidea. In its present composition, the family Dilepididae is a heterogeneous group. This is also the opinion of Bona (1994) who believed that the 100 genera referred to this family do not form a monophyletic assemblage and suggested further studies in order to elaborate a new suprageneric arrangement of the group.

Until now, the species of the genus Burhinotaenia were known only from Europe, Africa, and south Asia (Spasskaya and Spasskii, 1978; Schmidt, 1986). This is the first record of cestodes of this genus in the New World.

\section{ACKNOWLEDGMENTS}

We are grateful to F. V. Bona (Torino) for providing unpublished information on Burhinotaenia spp. and to C. Vaucher
(Geneva) for lending the type specimens of $B$. delachauxi. This investigation was supported by the National Scientific Research Foundation of the Republic of Bulgaria, grants B-44/1991 and B-404/1994 (to B.B.G.).

\section{LITERATURE CITED}

BAER, J. G. 1925. Cestodes nouveaux du Sud-Ouest de l'Afrique. Revue suisse de Zoologie 31: 529-548.

- 1959. Helminthes Parasites. In Explorations des Parcs Nationaux du Congo Belge. Mission J. G. Baer-W. Gerber (1958). Fascicule 1. Institut des Parcs Nationaux du Congo Belge, Bruxelles, Belgium, p. 1-163.

BEDDARD, F. E. 1913. Contribution to the anatomy and systematic arrangement of the Cestoidea. XI. On a new tapeworm from Oedicnemus. Proceedings of the Zoological Society of London 58: 861877.

BonA, F. V. 1994. Family Dilepididae Railliet \& Henry, 1909. In L. F. Khalil, A. Jones, and R. A. Bray (eds.). Keys to cestode parasites of vertebrates. CAB International, Wallingford, U.K., p. 443-554.

FunRmanN, O., AND J. G. BAER. 1943. Mission biologique Sagar-Omo (Ethiopie méridionale), 1939, dirigée par le professeur Eduardo Zavattari. Cestodes. Bulletin de la Société Neuchâteloise des Sciences Naturelles 68: 113-140.

HowARD, R., AND A. MOORE. 1980. A complete checklist of the birds of the world. Oxford University Press, Oxford, U.K., 701 p.

KoRNYUSHIN, V. V., AND B. B. GeORGIEV 1994. Family Metadilepididae Spasskii, 1959. In L. F. Khalil, A. Jones, and R. A. Bray (Eds.). Keys to cestode parasites of vertebrates. CAB International, Wallingford, U.K., p. 585-593.

Mahon, J. 1954. Tapeworms from the Belgian Congo. Annales du Musée Royal du Congo Belge, C, Zoologie, Séries V 1: 135-263.

MuraI, E., T. SUlgostowsKa, AND F. TenORA 1988. Tapeworm parasites of Burhinus oedicnemus (L., 1758) in Hungary (Cestoda: Progynotaeniidae and Dilepididae). Acta Zoologica Hungarica 34: 379-392.

SCHMIDT, G. D. 1986. Handbook of tapeworm identification. CRC Press, Boca Raton, Florida, 675 p.

SpASSKAYA, L. P., AND A. A. SpASSKII. 1978. Cestodes of birds in the USSR. Dilepidids of aquatic birds. Izdatel'stvo 'Nauka,' Moscow, 315 p. [In Russian.]

Spasskil, A. A., AND L. P. SpasskayA. 1965. Revision of the genus Paricterotaenia (Cestoda: Dilepididae). Parazity Zhivothykh i Rasteniy 1: 84-103. [In Russian.] 